\title{
Evaluation of Three Satellite Precipitation Products TRMM 3B42, CMORPH, and PERSIANN over a Subtropical Watershed in China
}

\author{
Junzhi Liu, ${ }^{1,2}$ Zheng Duan, ${ }^{3}$ Jingchao Jiang, ${ }^{4}$ and A-Xing Zhu ${ }^{1,2,4,5}$ \\ ${ }^{1}$ Key Laboratory of Virtual Geographic Environment, Ministry of Education, Nanjing Normal University, \\ 1 Wenyuan Road, Nanjing, Jiangsu 210023, China \\ ${ }^{2}$ Jiangsu Center for Collaborative Innovation in Geographical Information Resource Development and Application, \\ 1 Wenyuan Road, Nanjing, Jiangsu 210023, China \\ ${ }^{3}$ Delft University of Technology, 2628 CN Delft, The Netherlands \\ ${ }^{4}$ State Key Lab of Resources and Environmental Information System, \\ Institute of Geographic Sciences and Natural Resources Research, Chinese Academy of Sciences, Beijing 100101, China \\ ${ }^{5}$ Department of Geography, University of Wisconsin-Madison, Madison, WI 53706, USA
}

Correspondence should be addressed to Jingchao Jiang; jjc1022@126.com

Received 28 June 2014; Revised 3 September 2014; Accepted 4 September 2014

Academic Editor: Eduardo García-Ortega

Copyright (C) 2015 Junzhi Liu et al. This is an open access article distributed under the Creative Commons Attribution License, which permits unrestricted use, distribution, and reproduction in any medium, provided the original work is properly cited.

\begin{abstract}
This study conducted a comprehensive evaluation of three satellite precipitation products (TRMM (Tropical Rainfall Measuring Mission) 3B42, CMORPH (the Climate Prediction Center (CPC) Morphing algorithm), and PERSIANN (Precipitation Estimation from Remotely Sensed Information using Artificial Neural Networks)) using data from 52 rain gauge stations over the Meichuan watershed, which is a representative watershed of the Poyang Lake Basin in China. All the three products were compared and evaluated during a 9-year period at different spatial (grid and watershed) and temporal (daily, monthly, and annual) scales. The results showed that at daily scale, CMORPH had the best performance with coefficients of determination $\left(R^{2}\right)$ of 0.61 at grid scale and 0.74 at watershed scale. For precipitation intensities larger than or equal to $25 \mathrm{~mm}$, RMSE\% of CMORPH and TRMM 3B42 were less than 50\%, indicating CMORPH and TRMM 3B42 might be useful for hydrological applications at daily scale. At monthly and annual temporal scales, TRMM 3B42 had the best performances, with high $R^{2}$ ranging from 0.93 to 0.99 , and thus was deemed to be reliable and had good potential for hydrological applications at monthly and annual scales. PERSIANN had the worst performance among the three products at all cases.
\end{abstract}

\section{Introduction}

Precipitation plays an important role in hydrological cycling and is indispensable forcing data for hydrological modelling. Because precipitation has high spatial heterogeneity and temporal variability, conventional precipitation measurements at point-based gauge stations usually cannot provide enough information for hydrological applications (e.g., distributed hydrological modelling) especially in areas with sparse stations $[1,2]$. In contrast, satellite remote sensing can provide the spatial precipitation data over large areas in a temporally continuous way. In recent years, satellite precipitation products have been developing rapidly and become a new and promising precipitation data source for various hydrological studies.

Currently there are several quasi-global high-resolution satellite precipitation products including TRMM (tropical rainfall measuring mission) multisatellite precipitation analysis (TMPA) [3], CMORPH (the climate prediction center (CPC) morphing algorithm) $[4,5]$, and PERSIANN (precipitation estimation from remotely sensed information using artificial neural networks) [6,7]. Because such products have global (or quasi-global) orientation, the performances of satellite precipitation products are expected to vary from 
place to place. It is thus necessary to evaluate the performances of satellite precipitation products with local rain gauge data before these products can be used with high confidence in a specific study area. Such evaluation and intercomparison can also help to identify the most accurate and appropriate satellite precipitation product among various alternatives.

A few studies have been done to evaluate the performances of satellite precipitation products in different regions. For example, Xue et al. [8] evaluated two versions of TRMM 3B42 (V6 and V7) products in the mountainous Wangchu Basin of Bhutan using rain gauge data. The results showed that TRMM 3B42 V7 products have a significant upgrade from the $3 \mathrm{~B} 42 \mathrm{~V} 6$ products in precipitation accuracy and can serve as inputs to distributed hydrological modelling in that study area. Stampoulis et al. [9] analysed the errors of the CMORPH and PERSIANN precipitation products using rainfall data derived from weather radar rainfall estimates over the Mediterranean during heavy precipitation events and found that CMORPH exhibited better performance than PERSIANN.

In this study, we mainly focus on the performances of satellite precipitation data in the Poyang Lake Basin of China, which is an important tributary of the Yangtze River. Li et al. [10] evaluated the TRMM 3B42 V6 product in Xinjiang catchment of Poyang Lake Basin. However, they used only five rain gauge stations for the $15,500 \mathrm{~km}^{2}$ catchment, which is too sparse to generate a comprehensive evaluation of satellite precipitation product in such a large area. Hu et al. [11] compared the performances of six satellite rainfall products, including TRMM 3B43 V6, TRMM 3B42RT V6, CMORPH, GSMaP MWR+, GSMaP MVK+, and PERSIANN, with ground rain gauges located in the Ganjiang watershed of the Poyang Lake Basin, but their evaluation was only performed at the monthly scale. Liu et al. [12] evaluated both V6 and V7 of TRMM 3B42 precipitation products using rain gauge data over the Meichuan watershed of the Poyang Lake Basin at multitemporal scales (daily, monthly, and annual). Nevertheless, multitemporal scale evaluations of other commonly used satellite precipitation products such as CMORPH and PERSIANN have not been conducted yet. This work is necessary to provide a comprehensive evaluation of various commonly used satellite precipitation products in the Poyang Lake Basin.

In addition, the grid-based satellite precipitation products were usually directly compared with the point-based rain gauge data in most existing studies $[10,11]$. However, there exists a significant discrepancy of spatial scales between pointed-based rain gauges and satellite grid pixels (e.g., $0.25^{\circ}$ spatial resolution), and precipitation could vary across a single satellite pixel. The scale discrepancy between grid-based and pointed-based data might lead to errors in evaluation [13]. Therefore, scale transformation should be conducted to make the scales of rain gauge data and satellite precipitation data consistent.

This paper aims to evaluate the performances of three commonly used satellite precipitation products (TRMM 3B42, CMORPH, and PERSIANN) in a representative watershed of the Poyang Lake Basin using dense rain gauge data at consistent temporal and spatial scales. Section 2 introduces the study area and the datasets. Section 3 presents the methods used in this study. Section 4 describes and discusses the evaluation results. Section 5 concludes and discusses the future research directions.

\section{Study Area and Datasets}

2.1. Study Area. The Meichuan watershed, a representative watershed of Poyang lake basin, was selected as the study area due to the availability of dense rain gauge network. It is located within $26^{\circ} 0^{\prime}-27^{\circ} 8^{\prime} \mathrm{N}$ and $115^{\circ} 36^{\prime}-116^{\circ} 38^{\prime} \mathrm{E}$ (Figure 1). The total drainage area is $6366 \mathrm{~km}^{2}$ and the elevation ranges from 151 to $1425 \mathrm{~m}$. The average slope over the watershed is $9 \%$. This watershed is characterized by subtropical wet climate with an annual mean air temperature of $17^{\circ} \mathrm{C}$ and annual mean precipitation of $1706 \mathrm{~mm}$.

\subsection{Datasets}

2.2.1. Rain Gauge Data. There are 52 rain gauge stations around the Meichuan watershed. The measured daily precipitation data from these 52 gauges were obtained from the Hydrologic Yearbooks published by the Hydrographic Office of Jiangxi Province in China. The available time period for daily precipitation data is 9 years covering 2001-2005 and 2007-2010 due to the data missing in 2006. These rain gauge data were considered as ground truth for evaluation of three satellite precipitation products in this study.

2.2.2. TRMM $3 B 42$ Precipitation Products. The TMPA products provide precipitation for the spatial coverage of $50^{\circ} \mathrm{N}-\mathrm{S}$ at the $0.25^{\circ} \times 0.25^{\circ}$ latitude-longitude resolution. The TRMM $3 \mathrm{~B} 42$ product is one type of the TMPA products, and it is calibrated and merged with monthly rain gauge data. More detailed information regarding the processing and generation of on TRMM $3 B 42$ can be found in [14]. The temporal resolution of TRMM $3 \mathrm{~B} 42$ is 3-hourly, thus allowing us to obtain daily precipitation for evaluation. The latest Version 7 TRMM 3B42 products can be freely downloaded from Goddard Earth Sciences Data and Information Services Center (http://mirador.gsfc.nasa.gov). There are two kinds of TRMM 3B42 data available, 3-hourly precipitation (corresponding to the eight time period per day, i.e., UTC 00, 03, 06, 09, 12, 15,18 , and 21) and daily aggregated precipitation. The daily aggregated precipitation is obtained by summing all 8 sets of 3-hourly precipitation totals for a given day. Fortunately, the daily rain gauge stations measured precipitation during the same period as daily aggregated TRMM products (from UTC 00 to UTC 24). Therefore, the daily aggregated TRMM 3B42 products were directly used in this study.

\subsubsection{CMORPH Precipitation Products. The CMORPH} products provide precipitation for the spatial coverage of $60^{\circ} \mathrm{N}-\mathrm{S}$. The previous CMORPH is a pure satellite precipitation product using only satellite observation data [4]. In the latest CMORPH Version 1.0, bias correction 

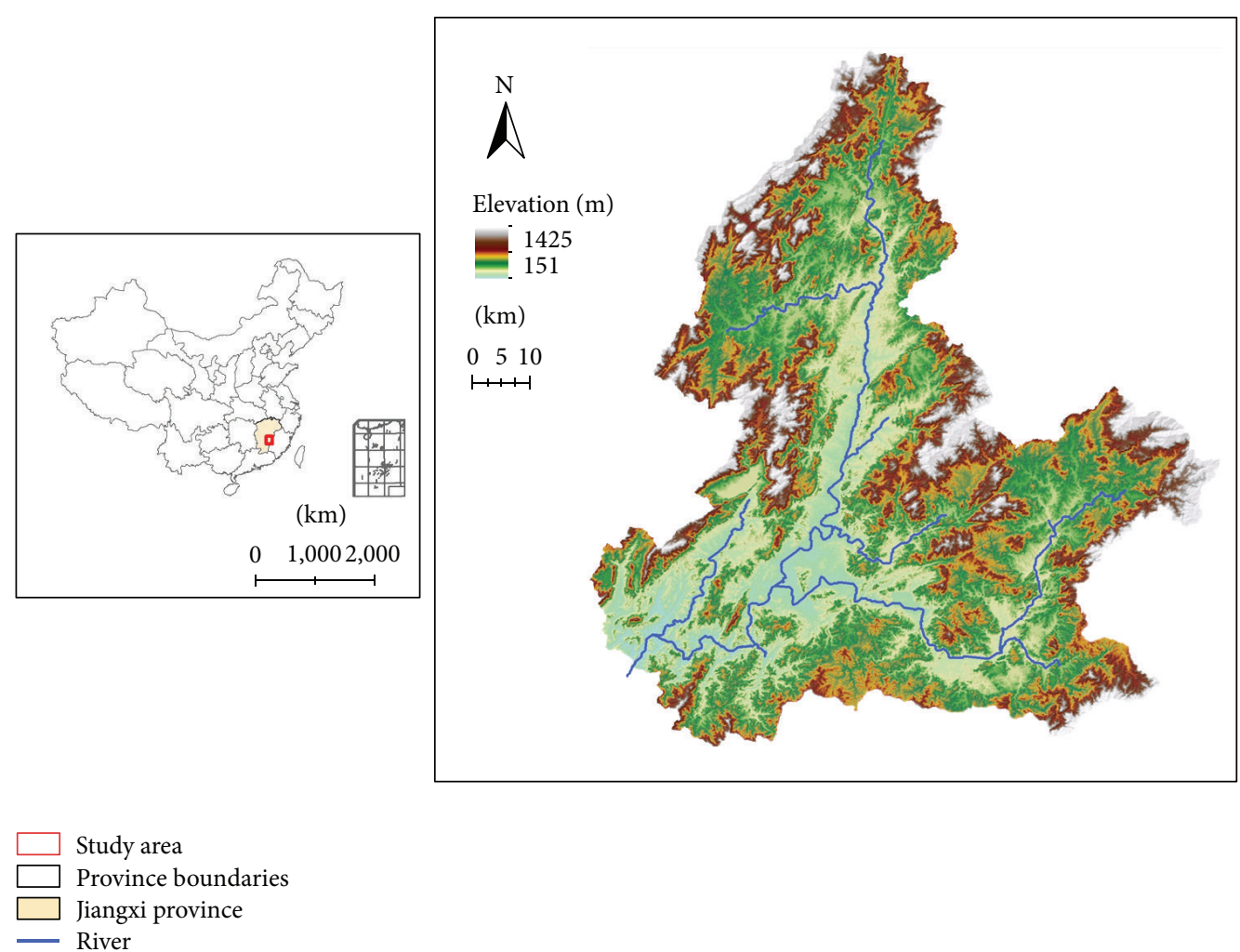

FIGURE 1: Location map of the study area.

was conducted by adjusting the satellite estimates against a daily rain gauge analysis [5]. The Version 1.0 CMORPH products can be accessed from the following website

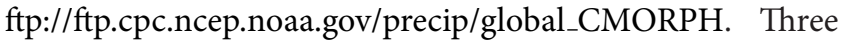
spatial and temporal resolutions can be selected: $8 \mathrm{~km}-$ $30 \mathrm{~min}, 0.25^{\circ}-3$ hourly, and $0.25^{\circ}$-daily. In this study, the $0.25^{\circ}$-daily bias-corrected Version 1.0 CMORPH data were used.

\subsubsection{PERSIANN Precipitation Products. The PERSIANN} products use the artificial neural network technique to estimate rainfall rate from satellite observations and have spatial quasi-global coverage of $60^{\circ} \mathrm{N}-\mathrm{S}$ [6]. Both raw PERSIANN product and bias-corrected PERSIANN product can be obtained from its product website. The bias-corrected PERSIANN precipitation maintains total monthly precipitation estimates to be consistent with GPCP (global precipitation climatology project) product. In this study, the bias-corrected PERSIANN data at the spatial resolution of $0.25^{\circ}$ and temporal resolution of 3-hourly were download from the following website http://fire.eng.uci.edu/PERSIANN/adj_persiann_3hr.html. The 3-hour data were then aggregated into daily values.

\section{Methodology}

For comprehensive evaluation, the comparison between the satellite precipitation data and the rain gauge data was conducted at two spatial scales: the grid scale and the watershed scale. For each spatial scale, three temporal scales (i.e., daily, monthly, and annual) were further performed for evaluation. For the evaluation at grid scale, the upscaling procedure was adopted to solve the scale discrepancy between the point-based rain gauge data and the grid-based satellite precipitation data. The rain gauge data were transformed into the areal precipitation at the same scale as satellite precipitation products (i.e., $0.25^{\circ}$ in this study). To achieve such transformation, many interpolation methods can be used, such as Thiessen polygon, IDW (inverse distance weighting), and Kriging. Since the Thiessen polygon method has been reported to be simple and robust [15], it was thus adopted in this study. In order to estimate the precipitation of each satellite grid from rain gauge data, the Thiessen polygons were then intersected with the satellite grid polygons. Figure 2 depicts the intersected polygons computed from Thiessen polygons and satellite precipitation grids. The grid-scale precipitation values were computed using the area weighted sum method from the rain gauge data, as shown in (1):

$$
V_{g}=\sum_{i=1}^{n} w_{i} V_{s i},
$$

where $V_{g}$ is the aggregated grid-scale precipitation, $n$ is the number of intersected Thiessen polygons within a grid, $w_{i}$ is the percentage of area for intersected Thiessen polygon $i$ in the grid, and $V_{s i}$ is the precipitation value of the intersected Thiessen polygon $i$.

After the scale transformation, grid-scale areal precipitation from rain gauge data was obtained and then used 


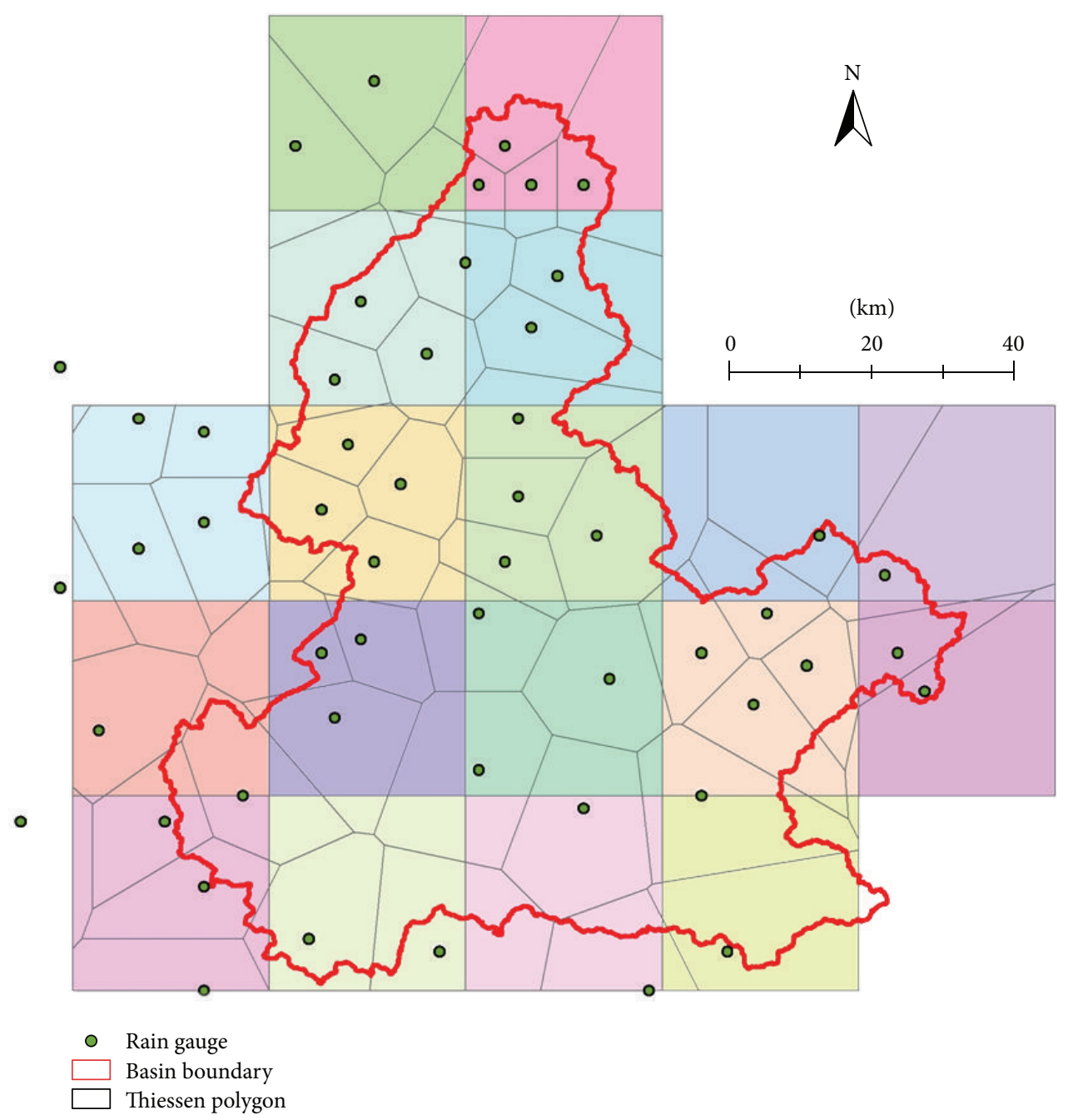

FIGURE 2: Intersection of Thiessen polygons (grey lines) with $0.25^{\circ} \times 0.25^{\circ}$ satellite grids, which are shown in different colors.

as ground truth for comparison with satellite precipitation data at a consistent scale. For the watershed-based evaluation, we first calculated the areal average precipitation of the whole watershed (i.e., average values of all the grids in the watershed) from satellite precipitation data and the rain gauge data, respectively. Then the comparison between these datasets was conducted.

Four statistical indictors were computed for the evaluation, that is, the coefficient of determination $\left(R^{2}\right)$, the bias, the root mean square error (RMSE), and the relative RMSE (labeled as RMSE\%). The $R^{2}$ represents the proportion of variability in one variable that is accounted for by another variable. For a linear regression model, $R^{2}$ is simply the square of the correlation coefficient between two variables. The bias reflects the degree to which the measured value is over- or underestimated [16]. The RMSE is a frequently used measure of differences between two variables. The RMSE\% is computed as RMSE divided by the mean precipitation of rain gauge data, and it can be used to evaluate the reliability of satellite precipitation product. When RMSE\% is less than $50 \%$, the satellite precipitation data are considered to be reliable, while they are unreliable when RMSE\% is equal to or is greater than $50 \%$ [17]. The formulas of the four indictors are described as follows:

$$
\begin{gathered}
R^{2}=\left[\frac{\sum_{i=1}^{n}\left(M_{i}-\bar{M}\right)\left(P_{i}-\bar{P}\right)}{\sqrt{\sum_{i=1}^{n}\left(M_{i}-\bar{M}\right)^{2}} \sqrt{\sum_{i=1}^{n}\left(P_{i}-\bar{P}\right)^{2}}}\right]^{2}, \\
\text { Bias }=\frac{\sum_{i=1}^{n} P_{i}}{\sum_{i=1}^{n} M_{i}}-1, \\
\text { RMSE }=\sqrt{\frac{\sum_{i=1}^{n}\left(P_{i}-M_{i}\right)^{2}}{n}}, \\
\text { RMSE } \%=\frac{\mathrm{RMSE}}{\bar{M}},
\end{gathered}
$$

where $P_{i}$ is grid scale or aggregated watershed scale precipitation from the satellite precipitation data, $M_{i}$ is the aggregated grid scale or watershed scale precipitation from rain gauge 
data, $n$ is the total number of data; $i$ is the index of data, $\bar{P}$ is the average value of $P_{i}$, and $\bar{M}$ is the average value of $M_{i}$.

\section{Results and Discussion}

\subsection{Evaluation Results at Daily Scale}

4.1.1. Overall Performance. Three satellite precipitation products (TRMM 3B42, CMORPH, and PERSIANN) were compared with the data of rain gauges at both the grid scale and the watershed scale. Figure 3 shows the scatter plots of data from rain gauge stations versus three satellite precipitation products at two spatial scales. There is no missing value in the TRMM 3B42 and CMORPH products, with 59166 data points for the grid-based evaluation and 3287 points for the watershed-based evaluation during the nine-year period. However, some missing values exist in the PERSIANN product, and there were no daily data available over the entire watershed during 17 days, leading to slightly fewer data points (Figure 3 ). The statistical indicators are also included in Figure 3.

TRMM 3B42 overestimated precipitation on the whole with a bias value of 0.04 , while CMORPH and PERSIANN underestimated precipitation with a bias value of -0.07 and -0.12 , respectively. At the grid scale, the CMORPH product had the best overall performance with $R^{2}$ of 0.61 and RMSE of $6.67 \mathrm{~mm} /$ day, and TRMM 3B42 ( $R^{2}$ of 0.52 and RMSE of $9.16 \mathrm{~mm} /$ day $)$ had better performance than PERSIANN $\left(R^{2}\right.$ of 0.39 and RMSE of $9.91 \mathrm{~mm} /$ day). This is perhaps because that the CMORPH product was calibrated using daily rain gauge analysis, while both TRMM 3B42 and PERSIANN products were calibrated using monthly precipitation data. At the watershed scale, as expected, these three types of satellite precipitation data showed a better agreement with the rain gauge data, with $R^{2}$ of 0.74 for CMORPH, 0.69 for TRMM $3 \mathrm{~B} 42$, and 0.49 for PERSIANN, respectively.

Since the performance of satellite estimates for relatively short time period (e.g., daily) often appears as a function of precipitation intensity [18], RMSE\% for different precipitation intensities (divided according to rain gauge data) was plotted in Figure 4. Generally, RMSE\% decreased with the increase of precipitation intensity for all the three precipitation products at both grid and watershed scales. At the grid scale, for precipitation less than $10 \mathrm{~mm}, \mathrm{RMSE} \%$ of all the three products was all high (larger than 350), while for precipitation larger than $10 \mathrm{~mm}$, RMSE\% all decreased dramatically (less than 100). RMSE\% at the watershed scale had similar trends to those at the grid scale and the RMSE\% values were smaller. CMORPH had the best performance among these three products, and TRMM 3B42 had better performance than PERSIANN. Although satellite precipitation products had relatively large errors for small precipitation, when precipitation intensities were larger than $50 \mathrm{~mm}$, the RMSE\% values of CMORPH and TRMM 3B42 at grid scale were close to or less than $50 \%$ (47.64 and 50.21 for CMORPH, 53.60 and 50.26 for TRMM 3B42 when precipitation intensities were $50-100 \mathrm{~mm}$ and $>100 \mathrm{~mm}$, resp.). When precipitation intensities were larger than $25 \mathrm{~mm}$, the RMSE\% values of
CMORPH and TRMM 3B42 at watershed scale were also less than 50\% (45.85 and 36.5 for CMORPH, 45.86 and 40.2 for TRMM 3B42 when precipitation intensities were $25-50 \mathrm{~mm}$ and $>50 \mathrm{~mm}$, resp.). These results indicated that CMORPH and TRMM 3B42 might have potential for daily hydrological applications.

4.1.2. The Performance of Capturing Storms. There were frequent severe floods in the recent decades over the Poyang Lake Basin, including the study area. Accurate estimation of extreme storms is of great importance for flood control and watershed management in this region. Therefore, it is necessary to evaluate the performance of the three satellite precipitation products in capturing storms. The Heidke skill score was adopted to evaluate the performance of different satellite precipitation products in capturing storms higher than a threshold [19]. Satellite precipitation estimations were divided into four cases according to whether they captured storms correctly: true positives (both satellite and rain gauge precipitation were higher than the threshold), false positives (satellite precipitation was higher than the threshold, while rain gauge precipitation was lower than the threshold), false negatives (satellite precipitation was lower than the threshold, while rain gauge precipitation was higher than the threshold), and true negatives (both satellite and rain gauge precipitation were lower than the threshold). The Heidke skill score (HSS) can be computed as

$$
\mathrm{HSS}=\frac{p-r_{\text {std }}}{1-r_{\text {std }}},
$$

where $r_{\text {std }}=((a+c) / n)((a+b) / n)+((b+d) / n)((c+d) / n)$, $p=(a+d) / n$, and $n=a+b+c+d, a, b, c, d$ means the numbers of occurrences of the above four cases (true positives, false positives, false negatives, and true negatives). The range of the HSS is $-t$ to 1 . A perfect set of predictions would be scored as 1.0, a set of random predictions would have an excepted score of zero, and sets of predictions having fewer hits than what would be excepted by chance would have negative scores. The HSS of three satellite precipitation products for storm thresholds ranging from $10 \mathrm{~mm}$ to $100 \mathrm{~mm}$ was plotted in Figure 5. Generally, the HSS decreased with the increase of storm threshold, and CMORPH had the best performance. At the grid scale, the HSS ranged from 0.2 to 0.6 , indicating that all satellite precipitation estimations at grid scale are better than chance performance. When the storm threshold was less than or equal to $60 \mathrm{~mm}$, the HSS of CMORPH were larger than 0.4, indicating that CMORPH captured moderate storms effectively. At the watershed scale, when the storm threshold was less than or equal to $80 \mathrm{~mm}$, the HSS of both CMORPH and TRMM was also larger than 0.4. But for the storm threshold of $100 \mathrm{~m}$, all the three products have HSS of around zero. This suggested that all the three satellite precipitation products could not capture extreme storms effectively, especially at watershed scale.

In order to further analyze the performance of satellite precipitation products in capturing extreme storms, the annual maximum daily precipitation and 5-day areal average precipitation at the watershed scale were computed from the 


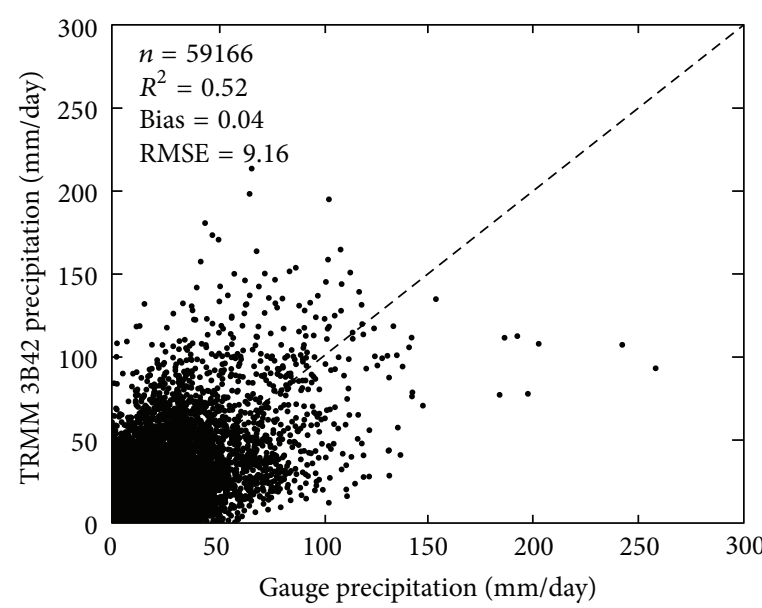

(a) TRMM 3B42 grid-scale

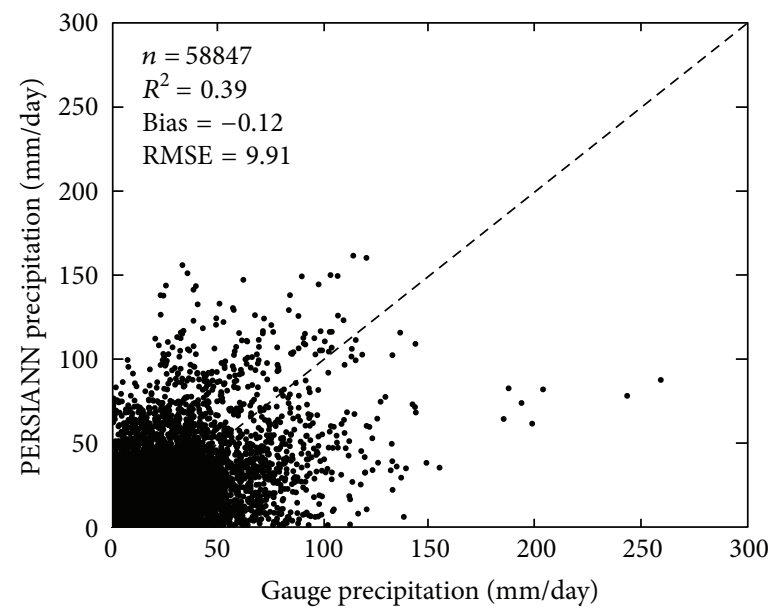

(c) PERSIANN grid-scale

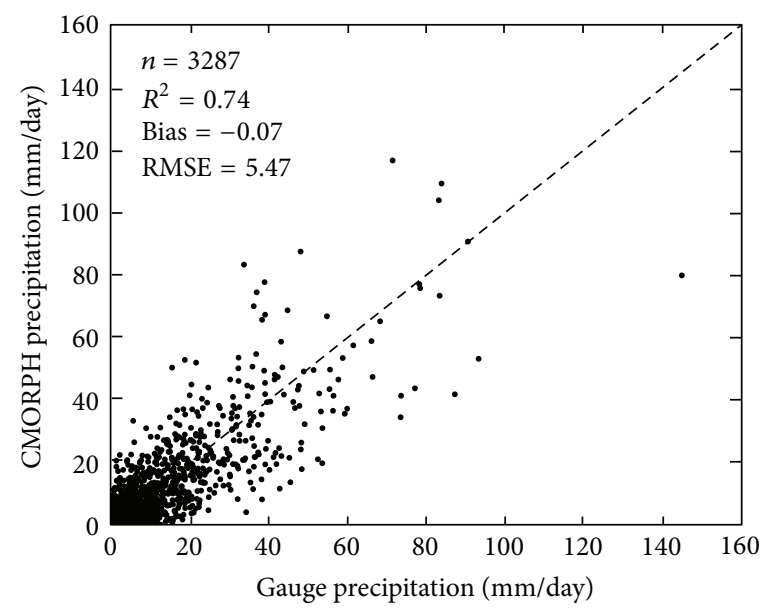

(e) CMORPH watershed-scale

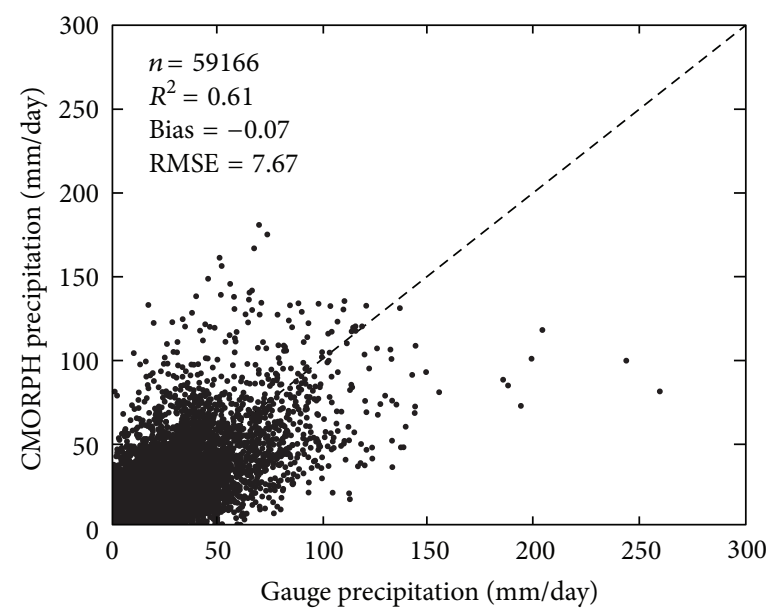

(b) CMORPH grid-scale

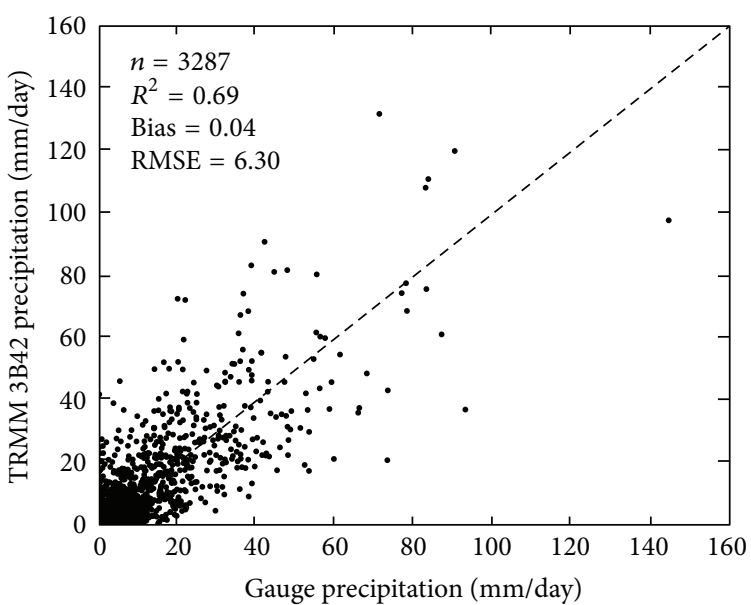

(d) TRMM 3B42 watershed-scale

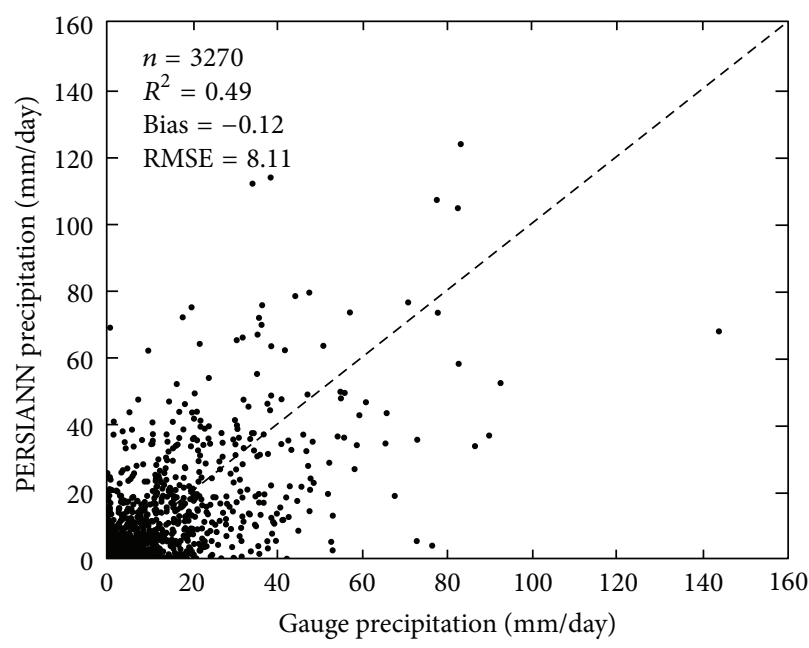

(f) PERSIANN watershed-scale

FIGURE 3: Scatter plots of daily precipitation from rain gauge stations versus three satellite products at grid and watershed scales. 


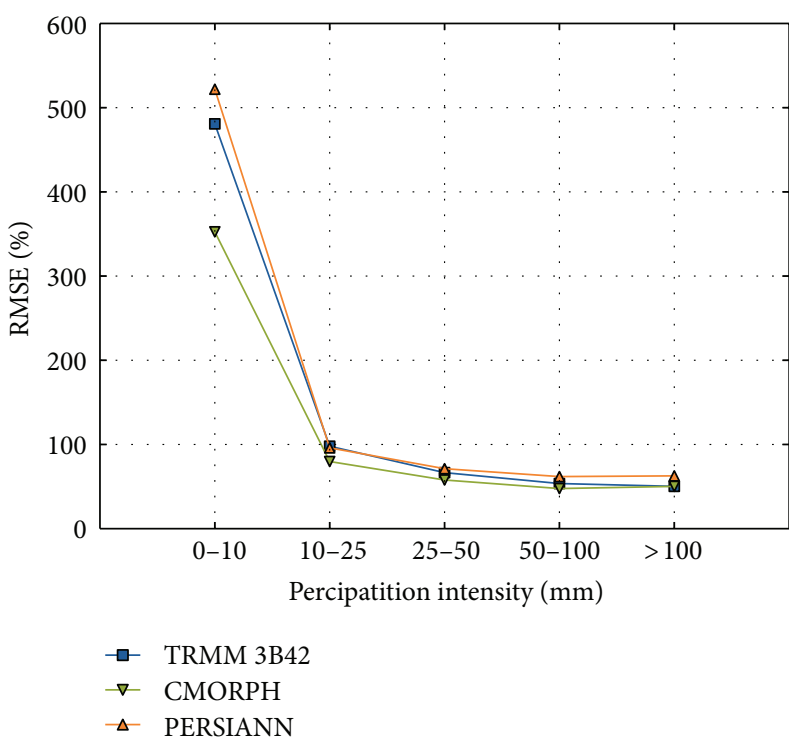

(a) Grid scale

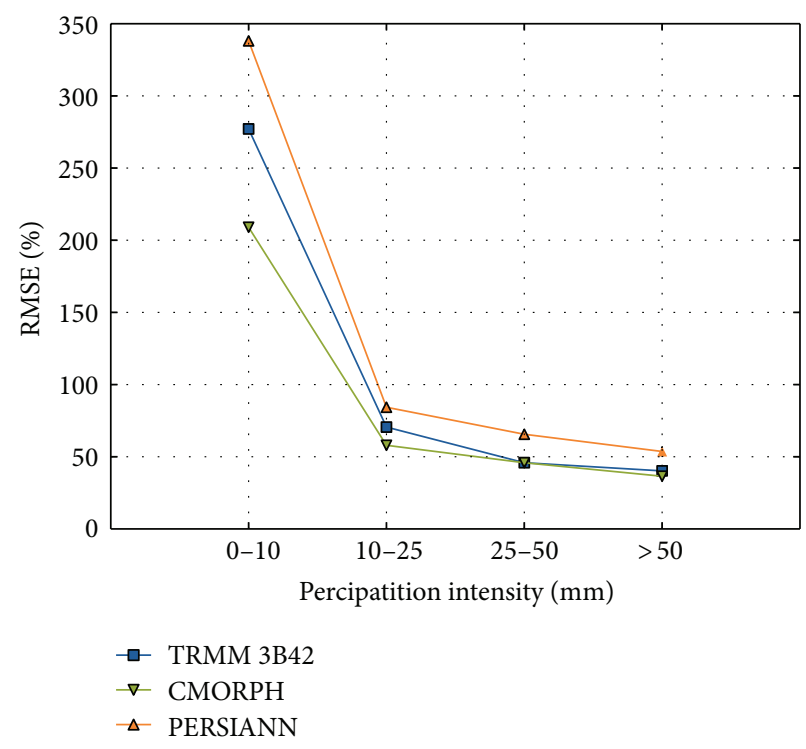

(b) Watershed scale

FIGURE 4: RMSE\% of satellite precipitation products (TRMM 3B42, CMORPH and PERSIANN) for different precipitation intensities (a) at grid scale and (b) at watershed scale.

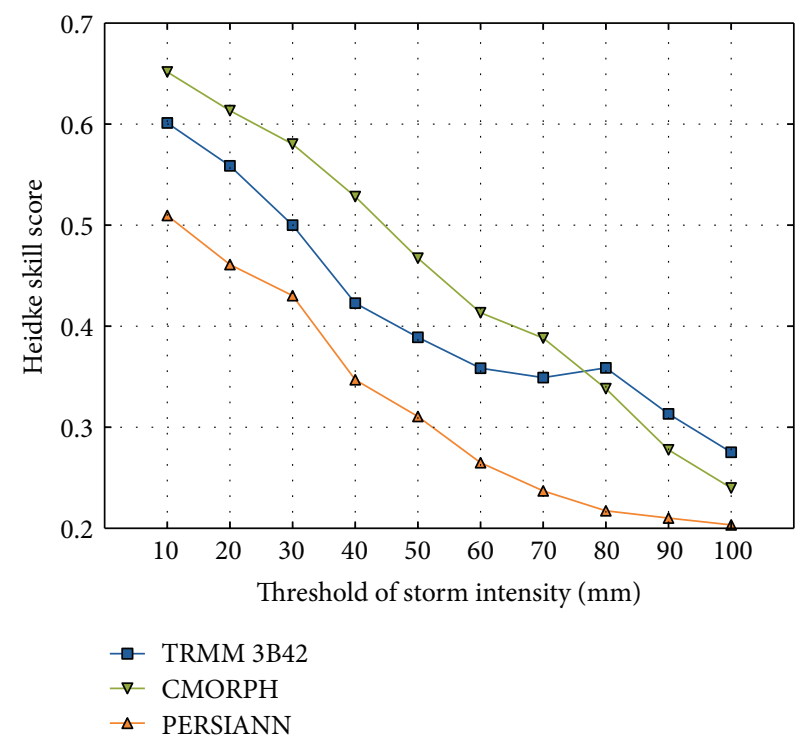

(a) Grid scale

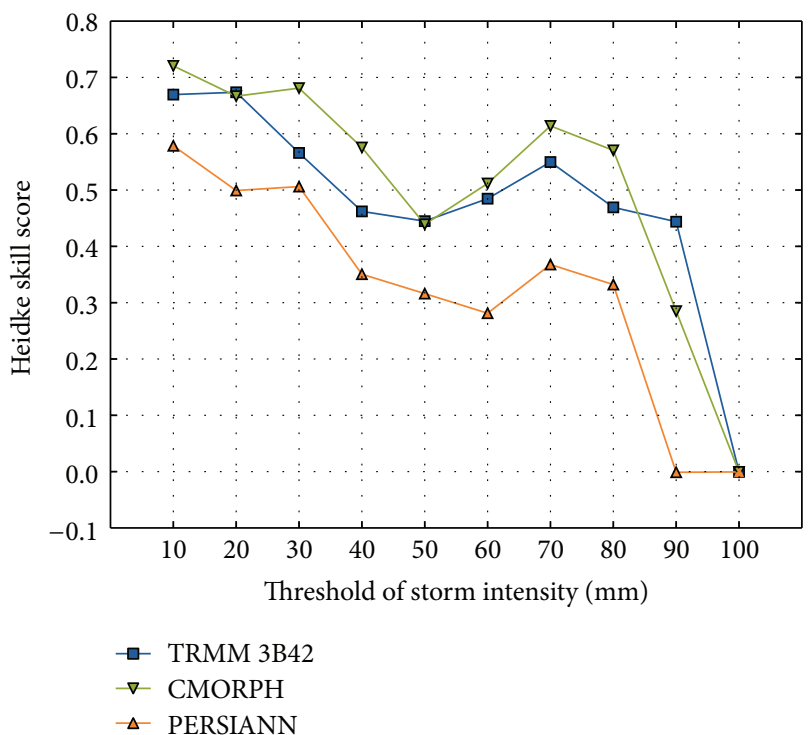

(b) Watershed scale

FIGURE 5: The Heidke skill score of three satellite precipitation products (TRMM 3B42, CMORPH and PERSIANN) for storm thresholds ranging from $10 \mathrm{~mm}$ to $100 \mathrm{~mm}$ (a) at grid scale and (b) at watershed scale.

rain gauge data and the three satellite precipitation products. As shown in Figure 6, there are obvious differences between the results obtained from the rain gauge data and the three satellite precipitation products. The statistics of the errors of maximum daily precipitation and 5-day satellite precipitation are shown in Table 1. TRMM 3B42 had the smallest average errors in estimating maximum daily precipitation, while CMORPH has the smallest average errors in estimating maximum 5-day precipitation. In terms of the maximum errors of both maximum daily precipitation and 5-day precipitation, TRMM 3B42 showed the best performance and CMORH had better performance than PERSIANN. However, even in the best case, the relative maximum errors reached $32.92 \%$ and $34.34 \%$ for the maximum daily precipitation and 5-day satellite precipitation, respectively. Therefore, all the three satellite precipitation products were deemed to have limited capabilities in capturing extreme storms because of their large relative errors. 
TABLE 1: The statistics of the errors of maximum daily and 5-day satellite precipitation during the nine-year period. The "relative (\%)" in the table is equal to absolute error divided by the corresponding precipitation of the rain gauge data.

\begin{tabular}{|c|c|c|c|c|c|c|c|}
\hline \multirow{2}{*}{ Index } & \multirow{2}{*}{ Product } & \multicolumn{2}{|c|}{ Minimum error } & \multicolumn{2}{|c|}{ Maximum error } & \multicolumn{2}{|c|}{ Average error } \\
\hline & & Absolute (mm) & Relative (\%) & Absolute (mm) & Relative (\%) & Absolute (mm) & Relative (\%) \\
\hline \multirow{3}{*}{ Max. daily precipitation } & TRMM 3B42 & 2.13 & 2.29 & 29.75 & 32.92 & 13.31 & 15.41 \\
\hline & CMORPH & 0.38 & 0.46 & 39.78 & 42.74 & 17.05 & 19.74 \\
\hline & PERSIANN & 7.94 & 9.58 & 55.99 & 99.65 & 30.46 & 35.27 \\
\hline \multirow{3}{*}{ Max. 5-day precipitation } & TRMM 3B42 & 4.58 & 3.64 & 123.94 & 34.34 & 43.01 & 22.97 \\
\hline & CMORPH & 4.74 & 1.84 & 160.56 & 44.48 & 39.83 & 21.28 \\
\hline & PERSIANN & 6.08 & 5.24 & 167.83 & 46.5 & 58.59 & 31.3 \\
\hline
\end{tabular}

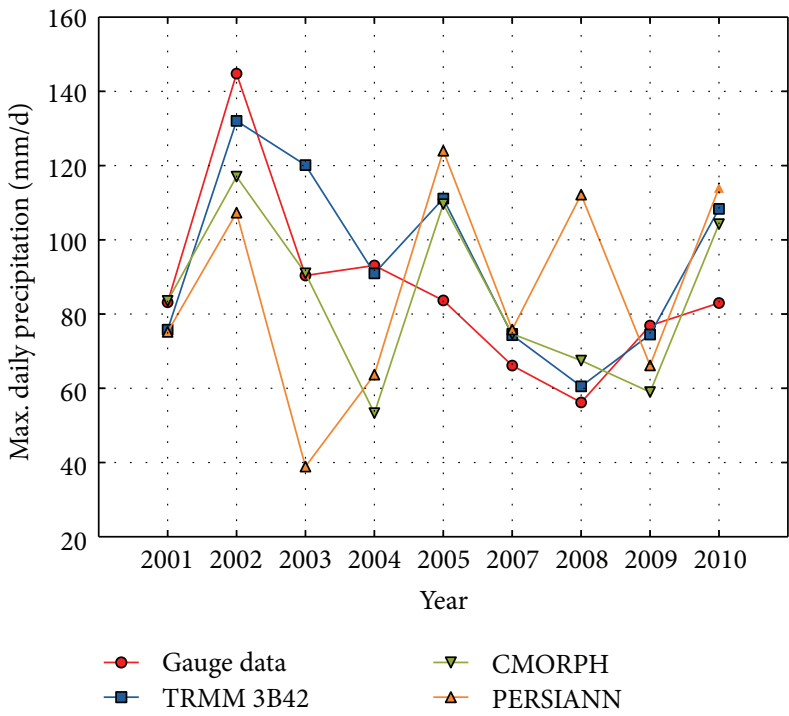

(a)

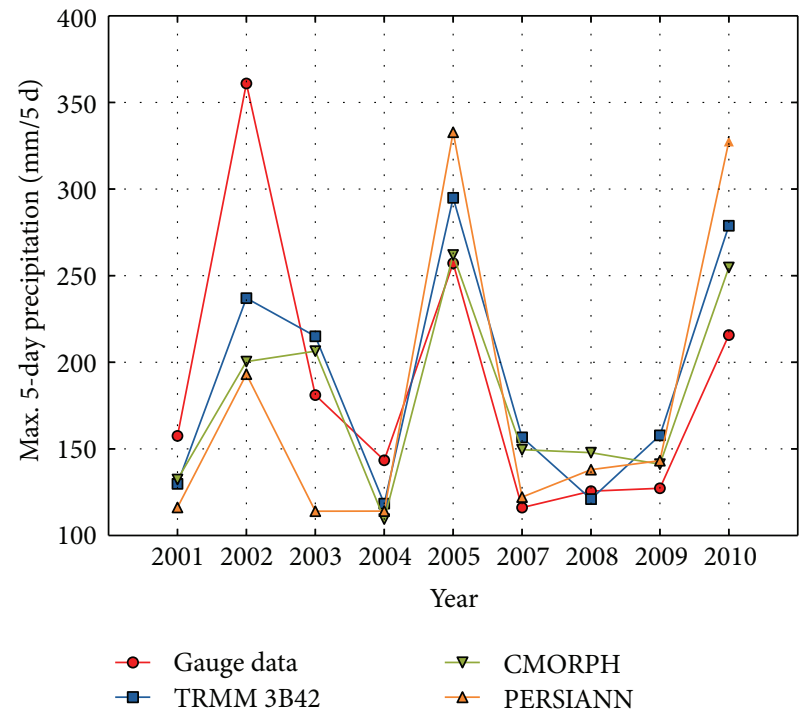

(b)

FIGURE 6: (a) Annual maximal daily and (b) maximal 5-day areal average precipitation at the watershed scale.

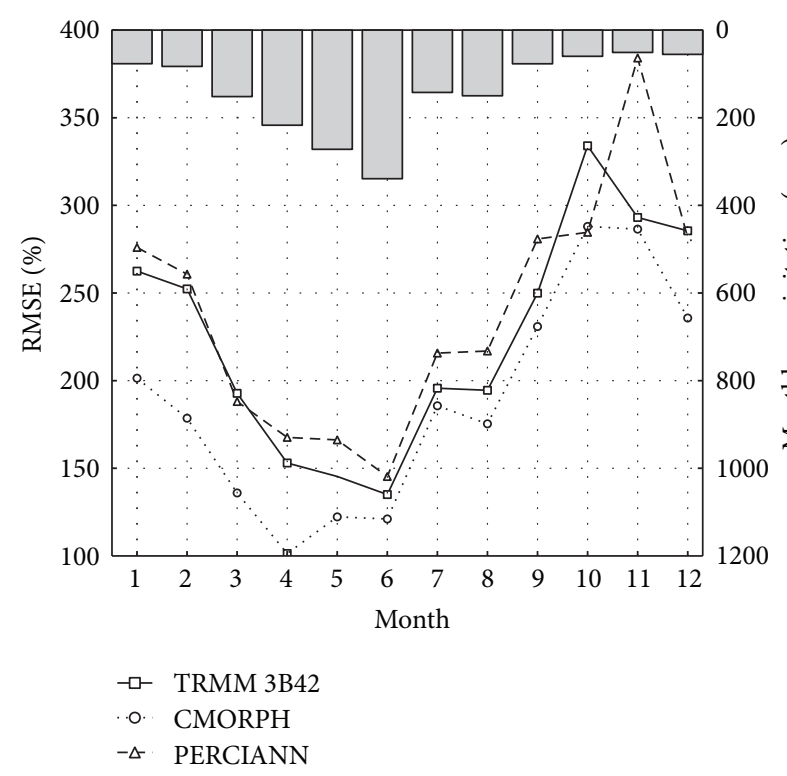

(a) Monthly variation of RMSE\%

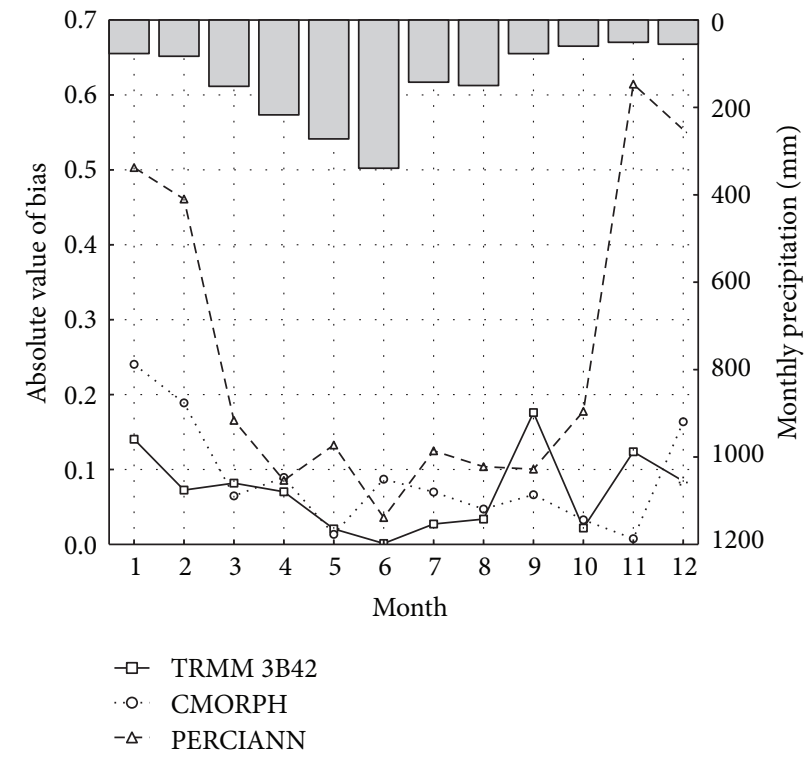

(b) Monthly variation of abs(bias)

FIGURE 7: Seasonal variation of (a) RMSE\% and (b) absolute value of bias of three satellite precipitation products (TRMM 3B42, CMORPH and PERSIANN) at the daily and grid scale. 


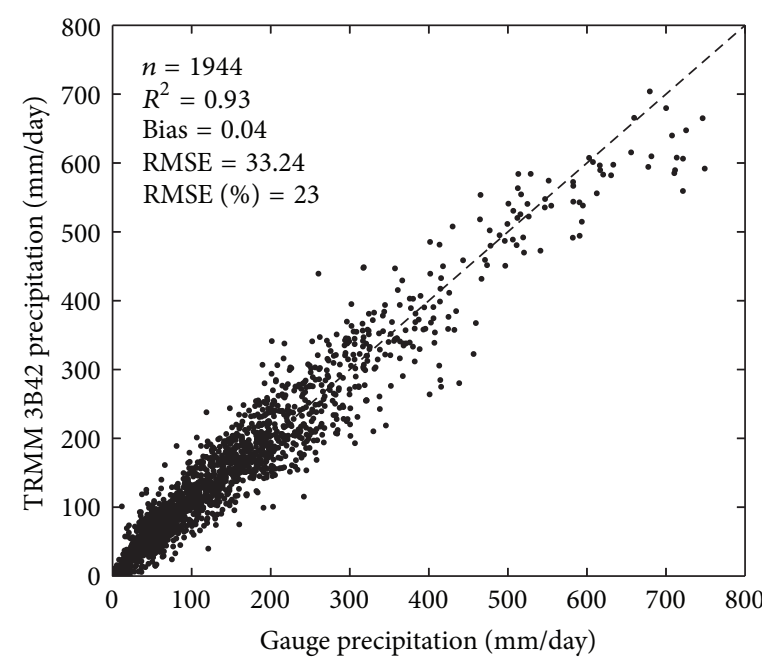

(a) TRMM 3B42 grid scale

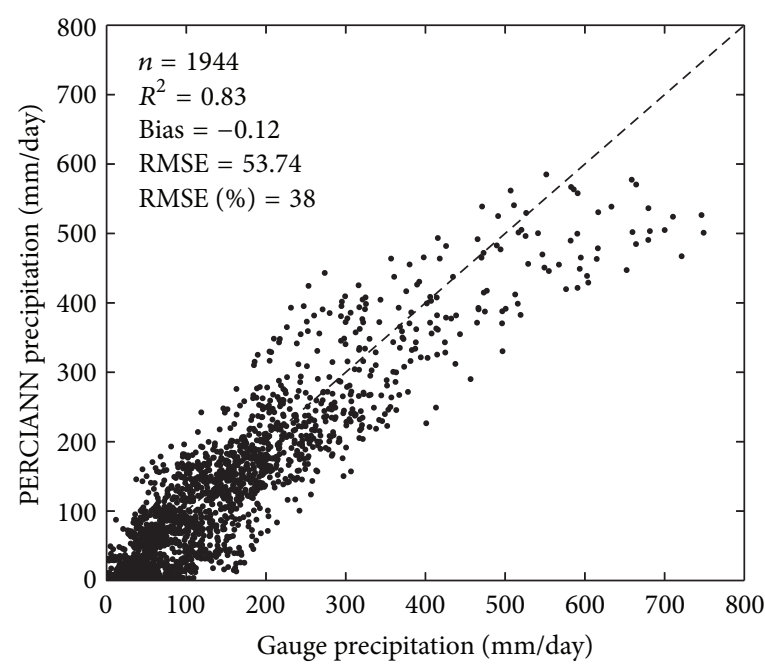

(c) PERCIANN grid scale

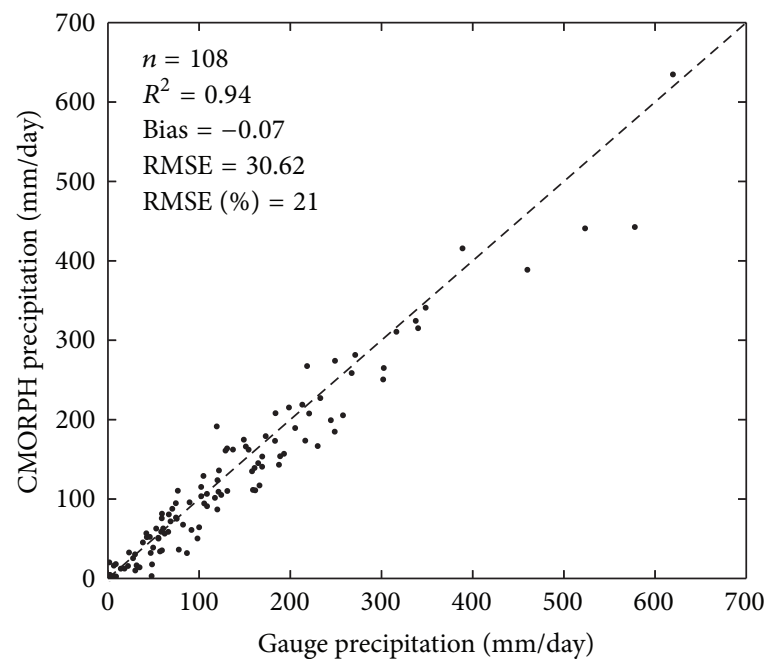

(e) CMORPH watershed scale

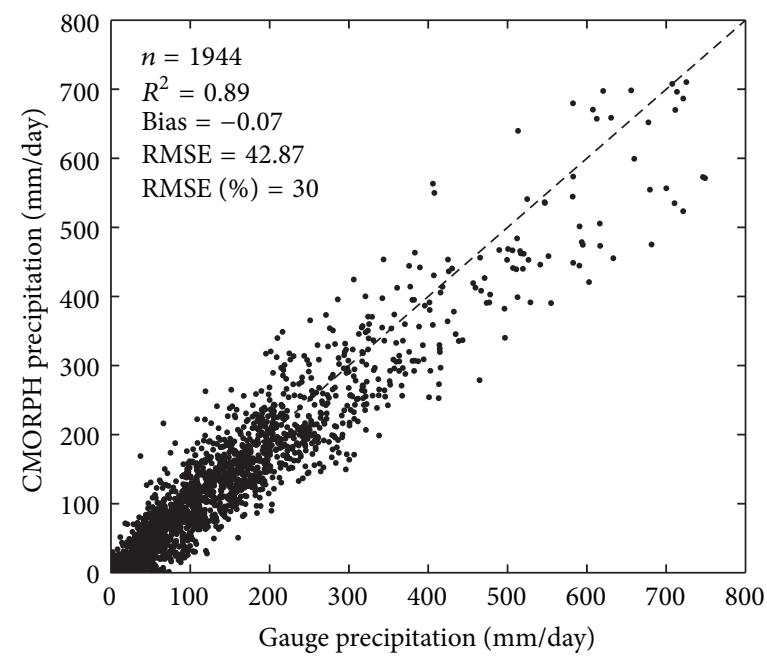

(b) CMORPH grid scale

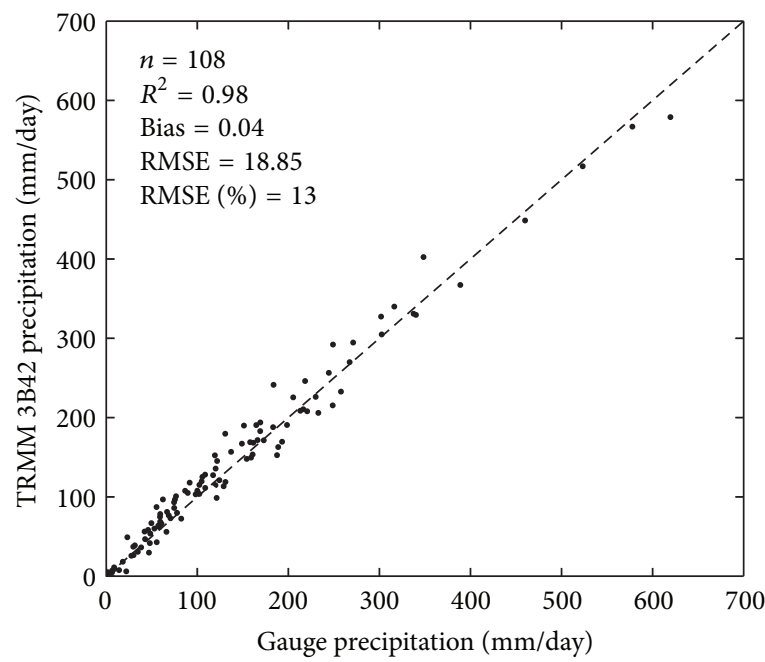

(d) TRMM 3B42 watershed scale

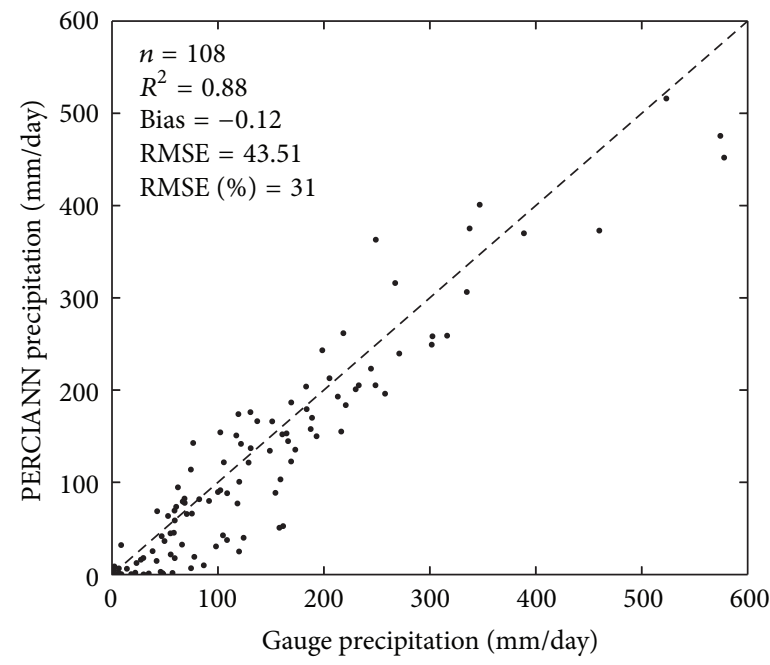

(f) PERCIANN watershed scale

FIGURE 8: Scatter plots of monthly precipitation from rain gauge stations versus three satellite products at grid and watershed scales. 
The results shown in Table 1 suggested that CMORPH and TRMM 3B42 might be useful for hydrological applications at daily scale. However, since all the three products had poor performances in the estimation of small precipitation values and extreme storms, local calibration with rain gauge (or ground radar) data using data assimilation methods (e.g., optimum interpolation) $[18,20,21]$ should be carried out to further improve the daily precipitation estimations before they are used in real-world hydrological applications at daily scale.

4.1.3. Seasonal Variation of Daily Accuracy. Figure 7 plots the seasonal variation of accuracy for these three satellite precipitation products (TRMM 3B42, CMORPH, and PERSIANN) at daily and grid scales. It is found that both RMSE\% and absolute value of bias showed seasonal fluctuations. In spring and summer, when it rains relatively more, the RMSE\% values were lower and the absolute values of bias were smaller. CMORPH had the smallest RMSE\%, and TRMM 3B42 had smaller RMSE\% than PERSIANN. The fluctuations of the accuracy of the PERSIANN product were the largest among the three satellite precipitation products, with very high RMSE\% values and absolute values of bias in the winter.

\subsection{Evaluation Results at Monthly Scale}

4.2.1. Overall Performance. The daily precipitation data were accumulated to monthly total precipitation for the rain gauge data and three satellite precipitation products (TRMM 3B42, CMORPH, and PERSIANN). The monthly total precipitation data from four datasets were compared at both the grid scale and the watershed scale. The results with statistical indicators are shown in Figure 6. There are totally 1944 comparison points at the grid scale and 108 points at the watershed scale during the nine-year period. Good agreements with the rain gauge data were observed for all the three satellite precipitation products at the grid scale, with $R^{2}$ of 0.93 for TRMM 3B42, 0.89 for CMORPH, and 0.83 for PERSIANN, respectively. As expected, such agreements are even better at the watershed scale with $R^{2}$ of 0.98 for TRMM 3B42, 0.94 for CMORPH, and 0.88 for PERSIANN. The higher accuracy at monthly scale than at daily scale is due to the fact that the errors at daily scale were nearly symmetrical (see Figure 3 ) and thus could cancel each other out after the aggregation. In terms of all four statistical indicators (Figure 8), TRMM 3B42 had the best performance at monthly scale, and PERSIANN had the largest errors.

4.2.2. Seasonal Variation of Monthly Accuracy. Figure 9 plots the seasonal variation of RMSE\% of three satellite precipitation products (TRMM 3B42, CMORPH, and PERSIANN) at monthly and grid scales. The results show that the RMSE\% values of all the three satellite precipitation products show seasonal fluctuations, with smaller RMSE\% values in spring and summer when the precipitation is relatively high. TRMM 3B42 had the smallest RMSE\% at monthly scale, and the RMSE\% values of TRMM 3B42 in April, May, and June were all below 20\%. The RMSE\% values of TRMM $3 B 42$

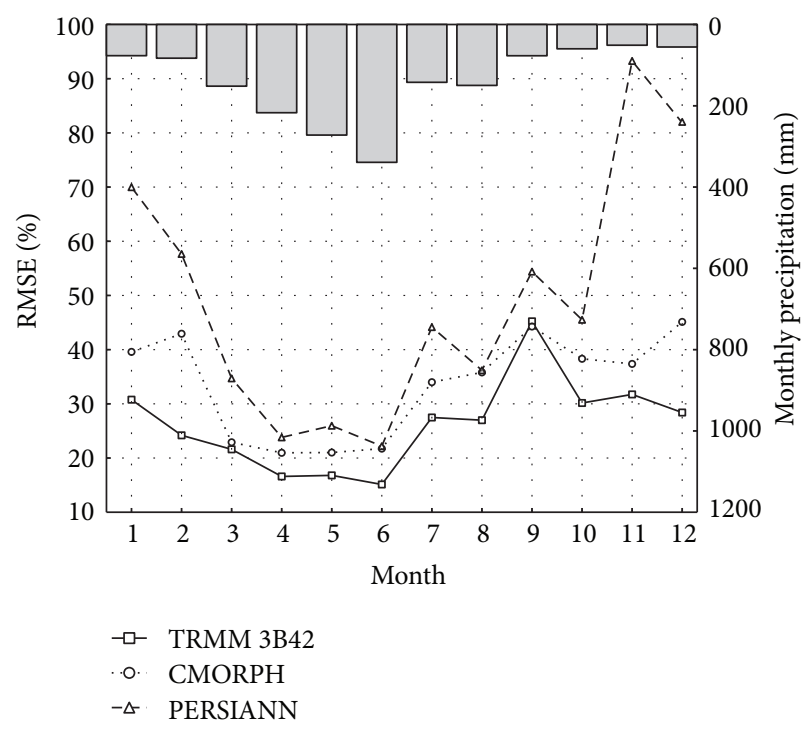

FIGURE 9: Seasonal variation of RMSE\% of three satellite precipitation products (TRMM 3B42, CMORPH, and PERSIANN) at monthly and grid scales.

and CMORPH in all months were below 50\%, indicating that these two satellite precipitation products have stable and acceptable accuracy and thus can be used in real-world hydrological applications at monthly scale. In all 12 months, PERSIANN had the largest errors among the three satellite precipitation products.

4.3. Evaluation Results at Annual Scale. The accumulated monthly precipitation data were further accumulated to annual total precipitation for the rain gauge data and the three types of satellite precipitation data. The annual precipitation data from the three satellite precipitation products (TRMM 3B42, CMORPH, and PERSIANN) are plotted versus those from the rain gauge data at two spatial scales in Figure 8. There are totally 162 data points at the grid scale and only 9 data points at the watershed scale during the nine-year period. The degree of reliability was improved as the aggregation in the temporal scale. All the three satellite precipitation products had high $R^{2}(0.84-0.99)$ and small relative RMSE (4\%-14\%). TRMM 3B42 had the best performance, and CMORPH had better performance than PERSIANN. It can be concluded that the annual accumulated precipitations from all three satellite precipitation products, especially TRMM 3B42, are reliable at both the grid scale and the watershed scale. However, Figure 10 clearly shows the tendency for overestimation by TRMM 3B42 but underestimation by both CMORPH and PERSIANN.

\section{Conclusions}

In this study, three satellite precipitation products (TRMM 3B42, CMORPH, and PERSIANN) were evaluated against rain gauge data during a nine-year period over the Meichuan watershed in China during a nine-year period. The evaluation 


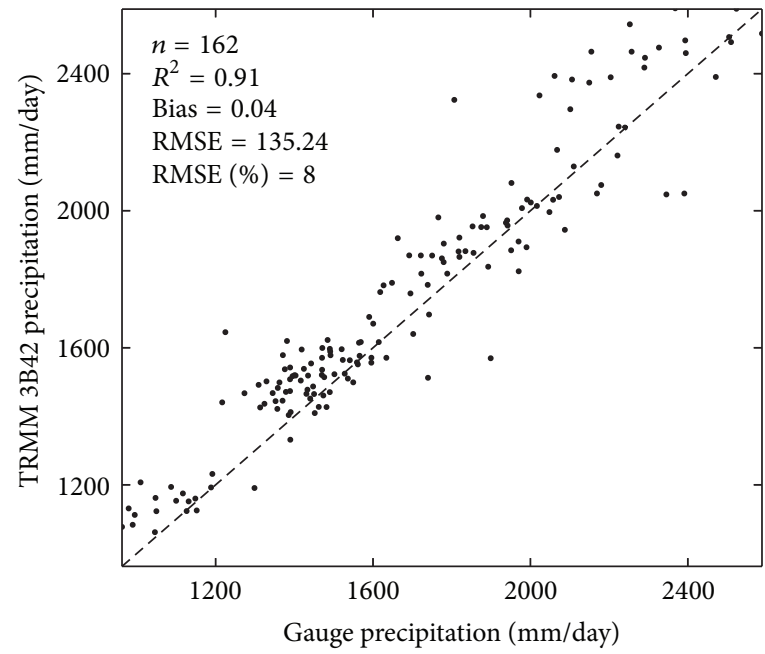

(a) TRMM 3B42 grid scale

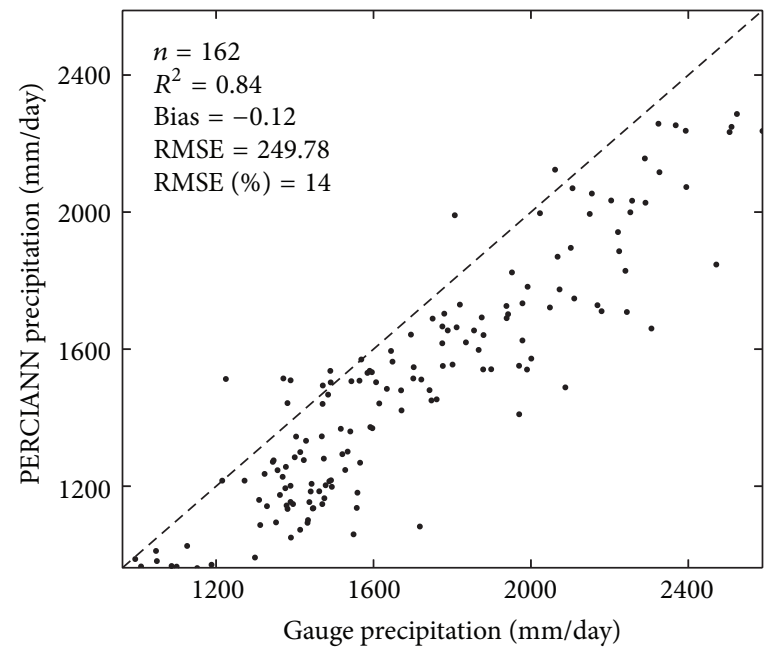

(c) PERCIANN grid scale

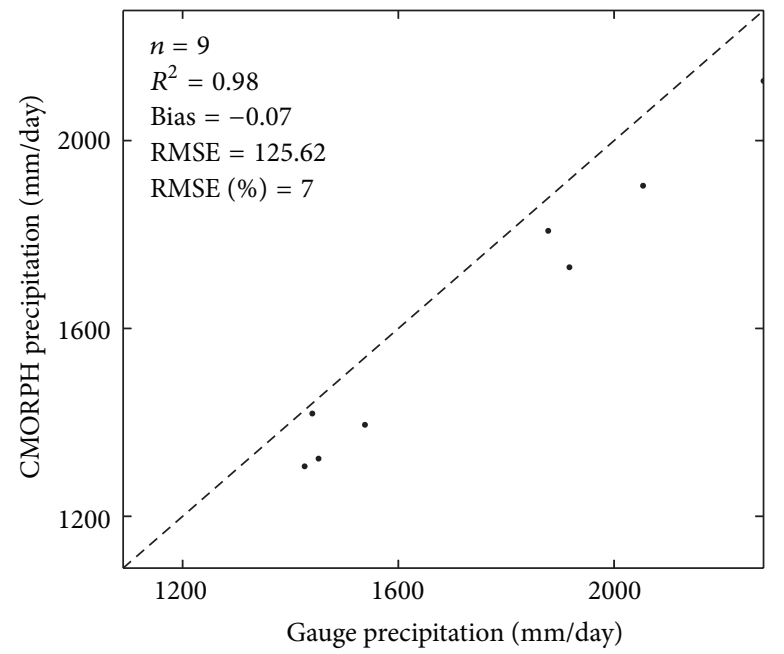

(e) CMORPH watershed scale

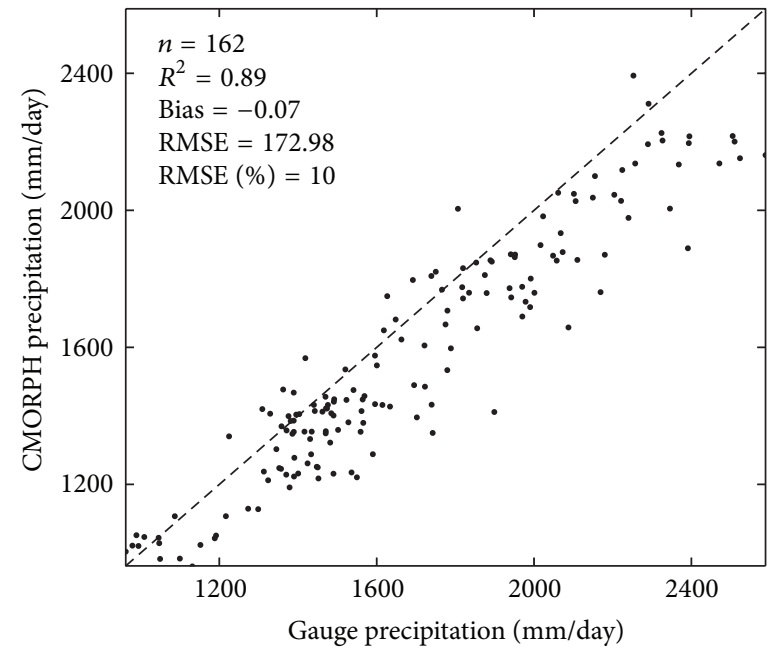

(b) CMORPH grid scale

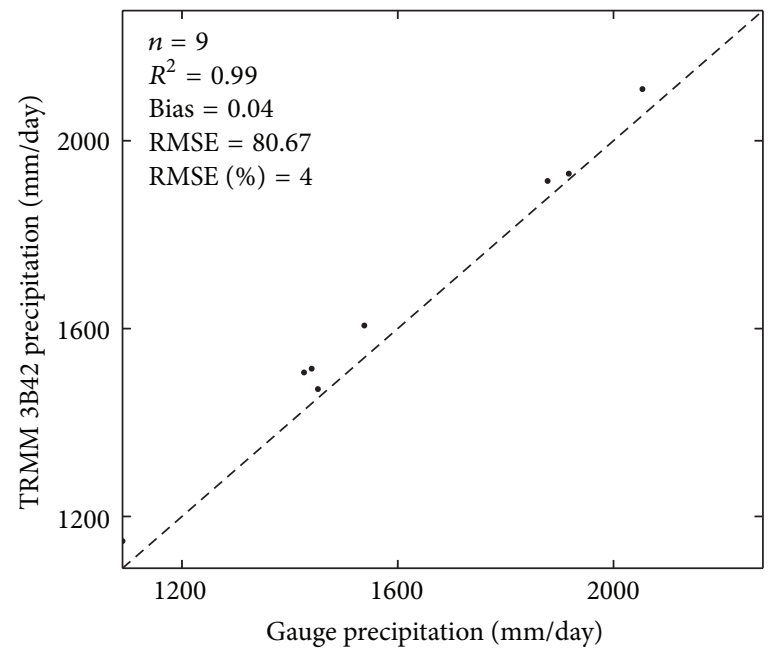

(d) TRMM 3B42 watershed scale

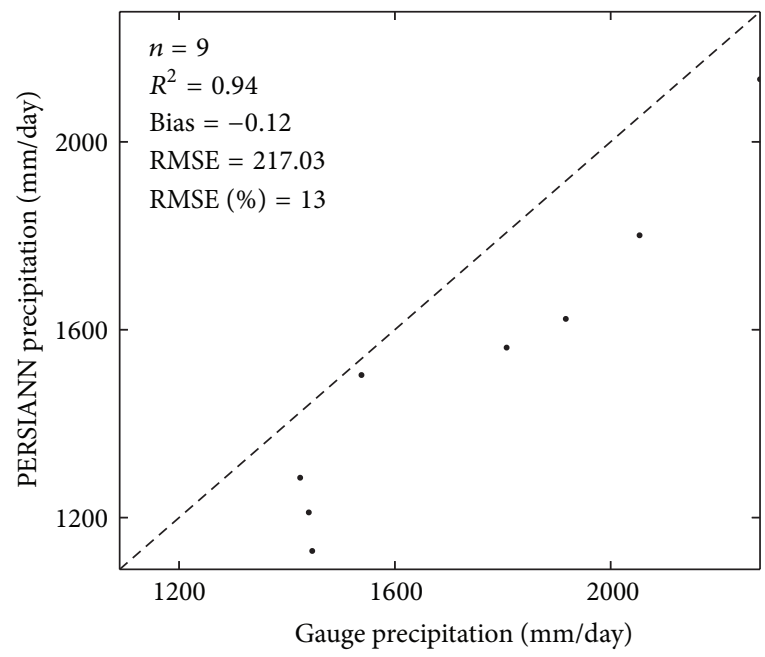

(f) PERCIANN watershed scale

FIGURE 10: Scatter plots of annual precipitation from rain gauge stations versus three satellite products at grid and watershed scales. 
was conducted at grid and watershed spatial scales and at daily, monthly, and annual temporal scales. For the evaluation at the grid scale, the point-based rain gauge data were first transformed to the consistent grid scale using the Thiessen polygon method for the grid versus grid comparison. At the watershed scale, average areal precipitation of the watershed was calculated by averaging values of all the grids in the watershed.

Comparisons with rain gauge data showed that, at daily scale, three satellite precipitation products had $R^{2}$ ranging from 0.39 to 0.61 at grid scale and ranging from 0.49 to 0.74 at watershed scale. For the precipitation intensities less than $25 \mathrm{~mm} / \mathrm{d}, \mathrm{RMSE} \%$ of all the three precipitation products exceeded $50 \%$ at watershed scale, while for precipitation intensities larger than or equal to $25 \mathrm{~mm}$, RMSE\% of CMORPH and TRMM 3B42 was less than 50\%. As far as the capability in capturing storms is concerned, all three products performed poorly in capturing extreme storms larger than $100 \mathrm{~mm} / \mathrm{d}$. However, the moderate to large storms $(<80 \mathrm{~mm})$ can be well captured by CMORPH and TRMM 3B42. These results suggested that CMORPH and TRMM 3B42 might be useful for hydrological applications at daily scale. However, because they had relatively poor performances in estimating small precipitation and extreme storms, local calibration with rain gauge or ground radar data should be carried out to further improve the daily precipitation estimates before they are used in real-world hydrological applications at daily scale. As the temporal scales increase, the performances of all the three satellite precipitation products were improved. At monthly and annual temporal scales, TRMM 3B42 had the best performances with high $R^{2}$ values ranging from 0.93 to 0.99 and low relative RMSE\% values ranging from $4 \%$ to $23 \%$. CMORPH and PERSIANN also had good performances at monthly and annual scales, all with $R^{2}$ values larger than 0.83 and RMSE\% values smaller than 38\%. Therefore, it can be concluded that satellite precipitation products, especially the TRMM 3B42 product, are reliable and have good potential for hydrological applications when they are used at monthly and annual scales. In addition, there were obvious seasonal fluctuations in the accuracies of all three precipitation products, with higher accuracies in wet seasons than in dry seasons. These seasonal fluctuations of accuracies should be considered when these satellite precipitation products are used in real-world applications.

In the future, hydrological simulations using satellite precipitation data as inputs should also be conducted in the Poyang Lake Basin to investigate whether the errors in satellite precipitation products can be tolerated by hydrological models.

\section{Conflict of Interests}

The authors declare that there is no conflict of interests regarding the publication of this paper.

\section{Acknowledgments}

This study was funded by the University Science Research Project of Jiangsu Province (no. 14KJB170009), the National
Natural Science Foundation of China (no. 41023010), the Thousand Talents Program of China, the Scientific Research Starting Foundation for High-level Scholars, Nanjing Normal University, and the Priority Academic Program Development of Jiangsu Higher Education Institutions.

\section{References}

[1] Z. Duan and W. G. M. Bastiaanssen, "First results from Version 7 TRMM 3B43 precipitation product in combination with a new downscaling-calibration procedure," Remote Sensing of Environment, vol. 131, pp. 1-13, 2013.

[2] V. Thiemig, R. Rojas, M. Zambrano-Bigiarini, V. Levizzani, and A. de Roo, "Validation of satellite-based precipitation products over sparsely Gauged African River basins," Journal of Hydrometeorology, vol. 13, no. 6, pp. 1760-1783, 2012.

[3] G. J. Huffman, R. F. Adler, D. T. Bolvin et al., "The TRMM Multisatellite Precipitation Analysis (TMPA): quasi-global, multiyear, combined-sensor precipitation estimates at fine scales," Journal of Hydrometeorology, vol. 8, no. 1, pp. 38-55, 2007.

[4] R. J. Joyce, J. E. Janowiak, P. A. Arkin et al., "CMORPH: a method that produces global precipitation estimates from passive microwave and infrared data at high spatial and temporal resolution," Journal of Hydrometeorology, vol. 5, no. 3, pp. 487503, 2004.

[5] P. Xie, S. H. Yoo, R. J. Joyce et al., "Bias-Corrected CMORPH: A 13-Year Analysis of High-Resolution Global Precipitation," 2011, http://ftp.cpc.ncep.noaa.gov/precip/CMORPH_V1.0/REF/EGU _1104_Xie_bias-CMORPH.pdf.

[6] K. L. Hsu, X. Gao, S. Sorooshian, and H. V. Gupta, "Precipitation estimation from remotely sensed information using artificial neural networks," Journal of Applied Meteorology, vol. 36, no. 9, pp. 1176-1190, 1997.

[7] S. Sorooshian, K.-L. Hsu, X. Gao, H. V. Gupta, B. Imam, and D. Braithwaite, "Evaluation of PERSIANN system satellitebased estimates of tropical rainfall," Bulletin of the American Meteorological Society, vol. 81, no. 9, pp. 2035-2046, 2000.

[8] X. Xue, Y. Hong, A. S. Limaye et al., "Statistical and hydrological evaluation of TRMM-based Multi-satellite Precipitation Analysis over the Wangchu Basin of Bhutan: are the latest satellite precipitation products $3 \mathrm{~B} 42 \mathrm{~V} 7$ ready for use in ungauged basins?" Journal of Hydrology, vol. 499, pp. 91-99, 2013.

[9] D. Stampoulis, E. N. Anagnostou, and E. I. Nikolopoulos, "Assessment of high-resolution satellite-based rainfall estimates over the mediterranean during heavy precipitation events," Journal of Hydrometeorology, vol. 14, no. 5, pp. 1500-1514, 2013.

[10] X.-H. Li, Q. Zhang, and C.-Y. Xu, "Suitability of the TRMM satellite rainfalls in driving a distributed hydrological model for water balance computations in Xinjiang catchment, Poyang lake basin," Journal of Hydrology, vol. 426-427, pp. 28-38, 2012.

[11] Q. Hu, D. Yang, Z. Li, A. K. Mishra, Y. Wang, and H. Yang, "Multi-scale evaluation of six high-resolution satellite monthly rainfall estimates over a humid region in China with dense rain gauges," International Journal of Remote Sensing, vol. 35, no. 4, pp. 1272-1294, 2014.

[12] J. Liu, A. X. Zhu, and Z. Duan, "Evaluation of TRMM 3B42 precipitation product using rain gauge data in meichuan watershed, Poyang Lake Basin, China," Journal of Resources and Ecology, vol. 3, no. 4, pp. 359-366, 2012.

[13] B. Yong, L.-L. Ren, Y. Hong et al., "Hydrologic evaluation of Multisatellite Precipitation Analysis standard precipitation 
products in basins beyond its inclined latitude band: a case study in Laohahe basin, China," Water Resources Research, vol. 46, no. 7, Article ID W07542, 2010.

[14] G. J. Huffman and D. T. Bolvin, "TRMM and Other Data Precipitation Data Set Documentation,” 2012, ftp://precip.gsfc.nasa .gov/pub/trmmdocs/3B42_3B43_doc.pdf.

[15] R. Grayson and G. Bloschl, Spatial Patterns in Catchment Hydrology: Observations and Modelling, Cambridge University Press, Cambridge, UK, 2001.

[16] Z. Duan, W. G. M. Bastiaanssen, and J. Z. Liu, "Monthly and annual validation of TRMM Mulitisatellite Precipitation Analysis (TMPA) products in the Caspian Sea Region for the period 1999-2003," in Proceedings of the International Geoscience and Remote Sensing Symposium (IGARSS '12), pp. 3696-3699, Munich, Germany, July 2012.

[17] S. H. Franchito, V. B. Rao, A. C. Vasques, C. M. E. Santo, and J. C. Conforte, "Validation of TRMM precipitation radar monthly rainfall estimates over Brazil," Journal of Geophysical Research D: Atmospheres, vol. 114, no. 2, Article ID D02105, 2009.

[18] P. Xie and A.-Y. Xiong, "A conceptual model for constructing high-resolution gauge-satellite merged precipitation analyses," Journal of Geophysical Research D: Atmospheres, vol. 116, no. 21, Article ID D21106, 2011.

[19] V. K. C. Venema, O. Mestre, E. Aguilar et al., "Benchmarking homogenization algorithms for monthly data," Climate of the Past, vol. 8, no. 1, pp. 89-115, 2012.

[20] M. Li and Q. Shao, "An improved statistical approach to merge satellite rainfall estimates and raingauge data," Journal of Hydrology, vol. 385, no. 1-4, pp. 51-64, 2010.

[21] K. J. Tobin and M. E. Bennett, "Adjusting satellite precipitation data to facilitate hydrologic modeling," Journal of Hydrometeorology, vol. 11, no. 4, pp. 966-978, 2010. 

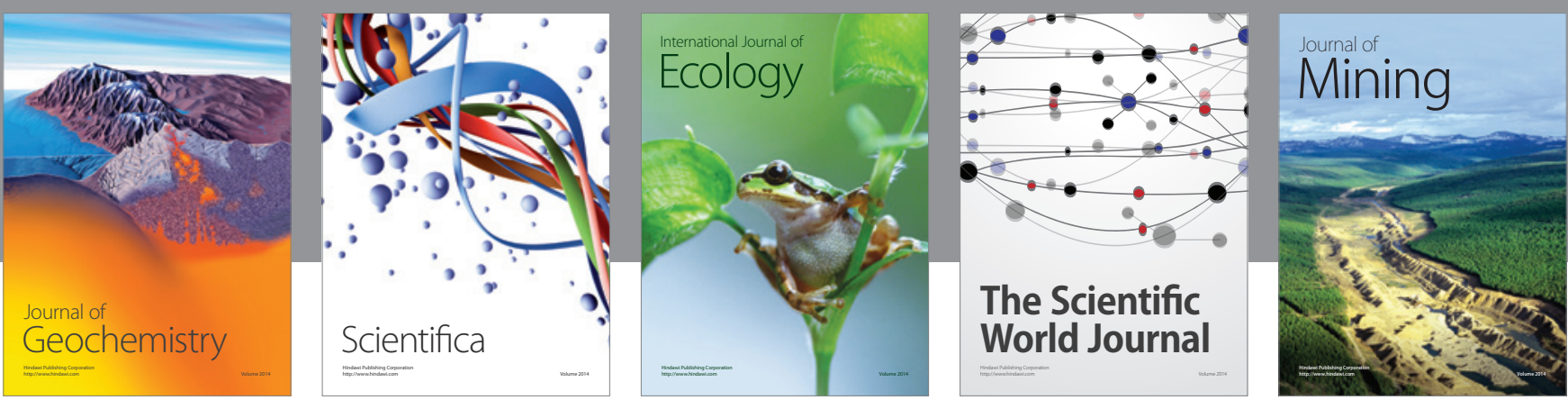

The Scientific World Journal
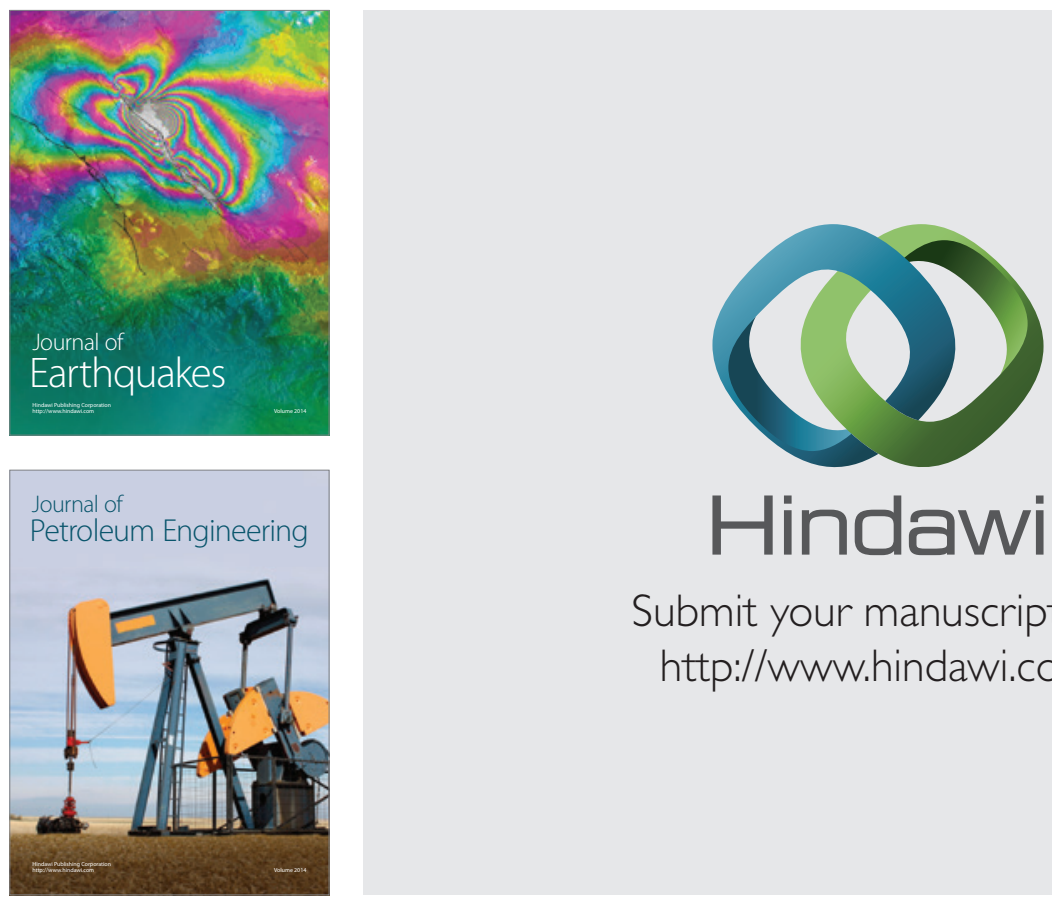

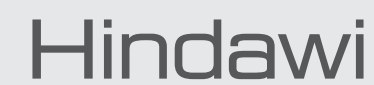

Submit your manuscripts at

http://www.hindawi.com
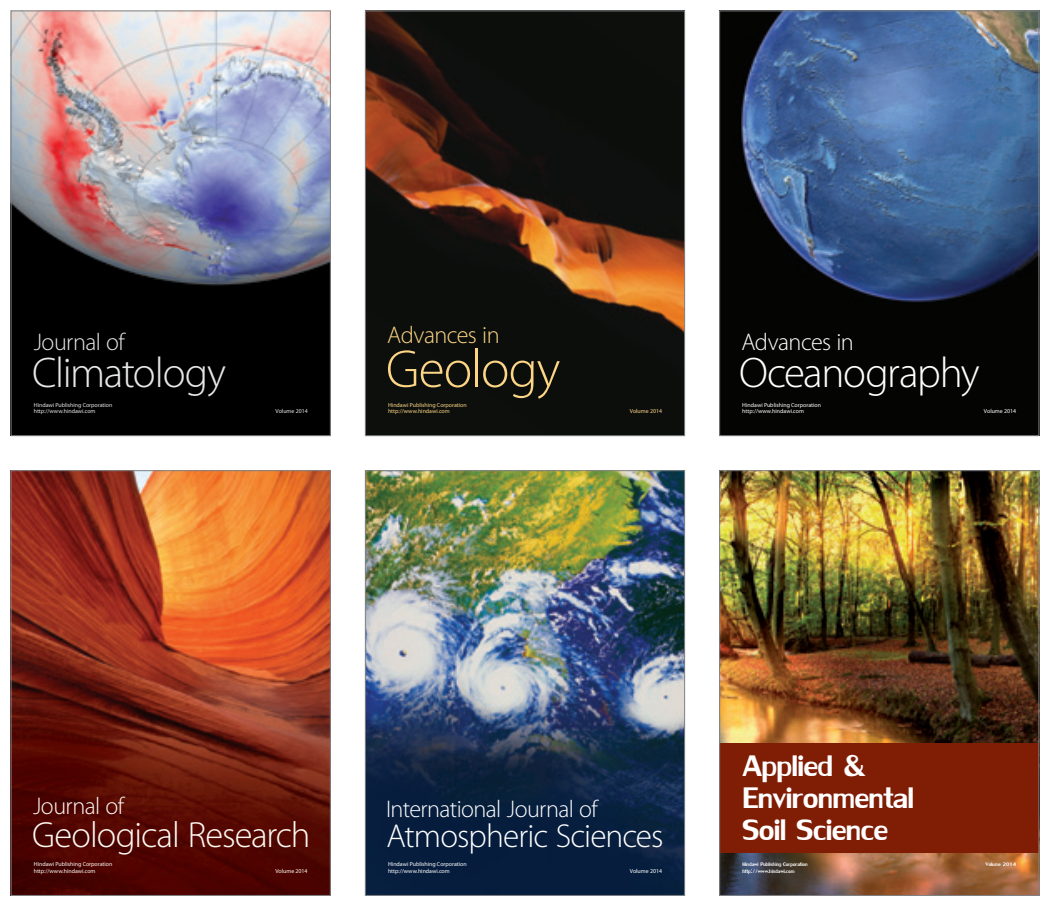
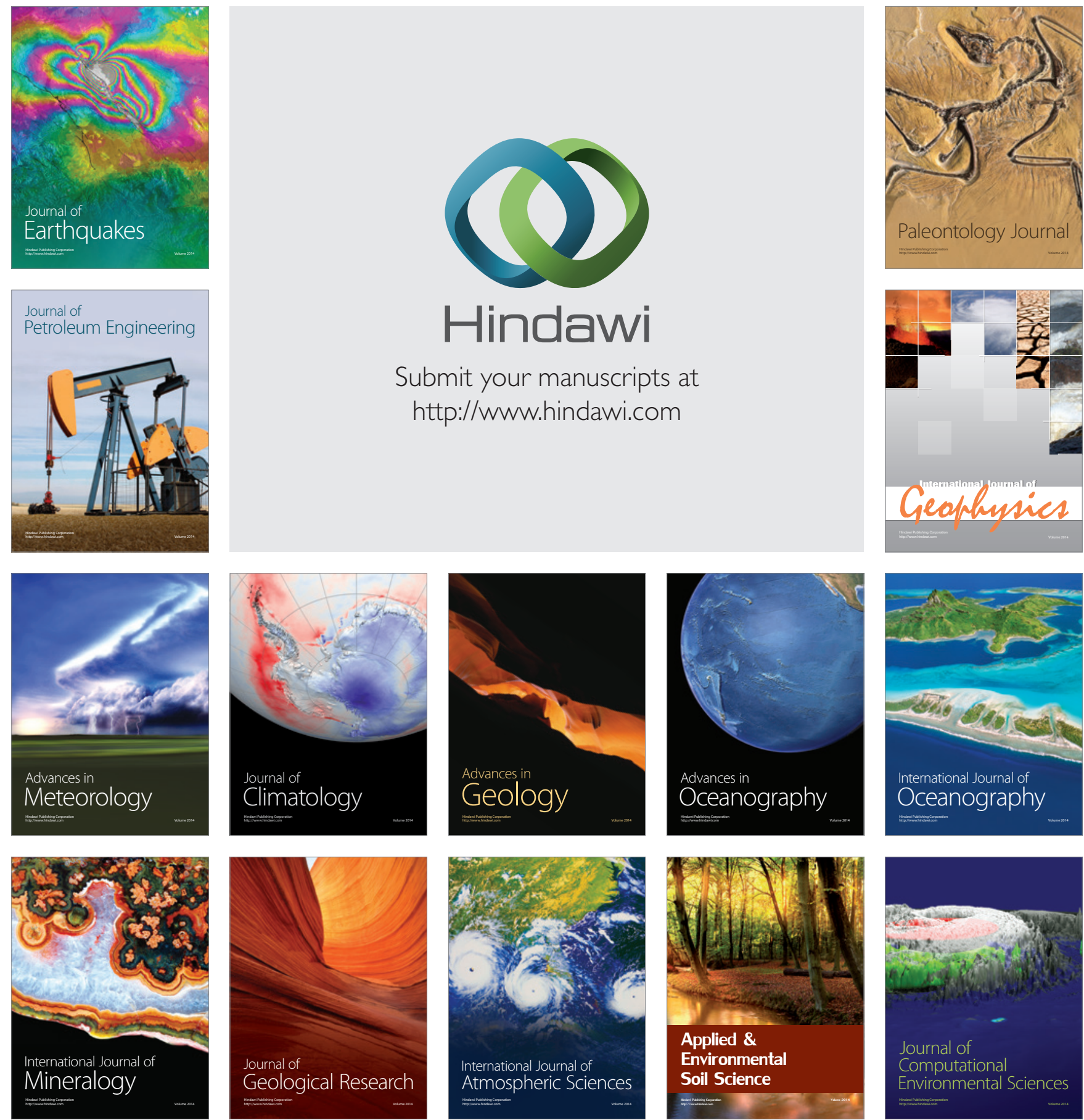